Original article

\title{
Contextual factors associated with sexual behavior among Brazilian adolescents
}

\author{
Maryane Oliveira-Campos BPT, MHS ${ }^{\mathrm{a}, \mathrm{b}, *}$, Luana Giatti MD, PhD ${ }^{\mathrm{a}, \mathrm{b}, \mathrm{c}}$, Deborah Malta MD, PhD ${ }^{\mathrm{d}}$, \\ Sandhi M. Barreto MD, PhD ${ }^{\text {a,b }}$ \\ a Department of Public Health, School of Medicine, Universidade Federal de Minas Gerais, Belo Horizonte, Brazil \\ ${ }^{\mathrm{b}}$ Research Group on Chronic and Occupational Diseases - GERMINAL, Universidade Federal de Minas Gerais, Belo Horizonte, Brazil \\ ${ }^{\mathrm{c}}$ School of Nutrition, Universidade Federal de Ouro Preto, Ouro Preto, Brazil \\ ${ }^{\mathrm{d}}$ Department of Surveillance of Non-Communicable Diseases, Health Surveillance Secretariat (SVS), Brasília, Brazil
}

\section{A R T I C L E I N F O}

\section{Article history:}

Received 25 November 2012

Accepted 8 March 2013

Available online 24 April 2013

\section{Keywords:}

Adolescent

Context

Family

School

Sexual behavior

Condom

Sexual risk

Unprotected sex

Sexually transmitted diseases

Adolescent pregnancy

\begin{abstract}
A B S T R A C T
Purpose: There are few studies about the influence of the context on sexual behavior among adolescents in developing countries, such as Brazil. Adolescent pregnancy and the high incidence of sexually transmitted disease (STDs) among Brazilian youngsters are a public health problem. The object of this study was to investigate whether factors from family and school contexts are associated with sexual behavior among Brazilian adolescents.

Methods: This study used data from 60,973 adolescent participants in the National Survey of School Health. The response variable was sexual behavior, described in three categories (never had sexual intercourse, had protected sexual intercourse, had unprotected sexual intercourse). The explanatory variables were grouped into sociodemographic characteristics, number of risk behavior factors (regular use of alcohol, smoking, and experimenting with illicit drugs), and family and school context. Variables associated with having protected and unprotected sexual relations in each context were identified by means of multinomial logistic regression. The reference was "never had sexual intercourse."

Results: Approximately one fourth of adolescents have already had sexual intercourse, most frequently boys. Among the adolescents who declared sexual initiation, the most part had their first sexual relation with age of 13 years or younger. Almost $21 \%$ did not use protection the last time they had sex. The greater the number of risk factors involved, the higher the incidence of protected and unprotected sex. In the family context, living with only one or with neither parent and low parental supervision increased the frequency of protected and unprotected sex. Never eating meals with the parents augmented the incidence of unprotected sex (odds ratio [OR], 1.60). In the school context, students from private schools were less likely to have had protected and unprotected sex (OR, 0.58 and 0.68$)$. Not receiving instructions at school about pregnancy prevention increased the frequency of protected and unprotected sex (OR, 1.33 and 1.74 , respectively).

Conclusions: Family and school context factors are associated with sexual behavior. These associations are generally stronger for unprotected sex. Information about the prevention of pregnancy and STDs/AIDS has to be disseminated very early owing to the young age of sexual initiation.
\end{abstract}

(c) 2013 Elsevier Inc. All rights reserved.

\section{Introduction}

Adolescent development is a complex and interactive process, which involves family, school, and the community in general [1]. Generally, adolescents spend most of their time at school or in a family environment. These contexts influence the health and

\footnotetext{
* Corresponding author. Programa de Pós-graduação em Saúde Pública, Faculdade de Medicina- Grupo de Pesquisa GERMINAL. Universidade Federal de Minas Gerais- UFMG. Avenida Alfredo Balena 100, sala 814, CEP: 30320-050, Belo Horizonte-Minas Gerais, Brazil. Tel.: +055 31-8800-0192; fax: +055 31-3248-9938.

E-mail address: oliveiracampos.m@gmail.com (M. Oliveira-Campos).
}

welfare of adolescents and have important impacts on adult life $[2,3]$. Since the 1990s, important social, cultural, and economic changes have occurred in Brazil. In addition to changes in the family composition caused mainly by the increase in the rate of divorces, remarriages, and single parenthood, the participation of Brazilian women in the labor market also increased [4].

Transformations in the family structure and in the parent-child relationship had several implications, such as the increase of adolescents' involvement with violence, the use of psychoactive substances, and sexual risk behaviors [5-7]. One of the most important events during adolescence is sexual initiation. According to ecological models, sexual behavior in adolescents is influenced by a large scope of circumstances, which range from individual and 
close context (friends, family, and school) to cultural, religious, and environmental factors $[1,8]$.

Scientific evidence reveals that certain factors from the family and school context can be protective against sexual risk behavior. Living with both parents and greater parental involvement and supervision have positive impacts, such as later sexual initiation, fewer sexual partners, and condom use [9-12]. At school, greater commitment and programs about sexual and reproductive health are associated with later sexual initiation and the use of protection [13-15].

Good family and school relationships are also associated with lower rates of sexually transmitted diseases (STDs) worldwide and undesired adolescent pregnancy $[15,16]$, public health problems that can be avoided with the use of condoms $[17,18]$. Unprotected sex is one of the factors that most contributes to increase the number of lost disability-adjusted life years among adolescents and young adults [19]. Undesired, unplanned pregnancy, besides compromising sexual and emotional development, is associated with school abandonment and future impoverishment [20,21].

In Brazil in 2006, $16.2 \%$ of the female adolescents between the age of 15 and 19 years were already moms; $13.5 \%$ had two children or more. Between 1996 and 2006, in the age range of 10 to 14 years, the number of births increased from 3 to 4 per 1000 women [22]. The high prevalence of STDs among young Brazilians also deserves attention. Comparing all age groups, young people (20 years or younger) are those who present the highest prevalence of chlamydia and human papillomavirus in the country [23]. The incidence of human immunodeficiency virus (HIV) is 2 in 100,000 men and 1.6 in 100,000 women among Brazilians aged 15 to 24 years [24].

Most studies published in Brazil regarding exposure to unprotected sex refer to older adolescents and young adults, or do not contain relevant information on the social contexts surrounding youngsters $[4,25]$. The few studies that collected information on these topics are small and restricted to a specific town or even school [26-28]. The National Survey of School Health (PeNSE) is the first comprehensive, nationally representative study to include information about both behavioral and social (family and school) contexts regarding Brazilian early adolescents.

The objectives of the present study were to describe the sexual behavior of adolescents in Brazilian schools and identify risk and protection factors in the family and school contexts associated with unprotected sex among this population, independent of individual, socioeconomic, and behavioral factors. Our hypothesis is that less parental involvement and supervision and poor access to information about sexual and reproductive health are associated with engaging in sexual intercourse and, especially, with engaging in unprotected sex.

\section{Methods}

The study analyzed data regarding 60,973 students who participated in the PeNSE, a cross-sectional study was undertaken by the Brazilian Ministry of Health among high school students in the 9th grade in public and private high schools from all 26 Brazilian State Capitals and the Federal District during May and June 2009. In each city, private and public schools were defined as two strata and the final sample was proportional to the size of the stratum in each municipality. Within each stratum, a cluster sampling was used where the primary sampling unit was the school. Within the school, one or two classes from the 9th grade were randomly selected depending on the school's size. All pupils in the randomly selected class were invited to participate.

\section{Procedures used in the study}

A self-administered questionnaire was used for data collection. The students answered the questions in a personal digital assistant, a palmtop computer. Participation was voluntary; the students had the choice of not answering. No information that could identify an individual student was obtained. All data regarding the school was confidential and was not included in the database. The research project was approved by the National Research Ethics Commission-CONEP (no 11.537). The methodology of the survey has been described in detail elsewhere [29].

\section{Measures}

In this study, the following variables were used to describe sexual behavior among the students: Having engaged in sexual intercourse at least once (defined by the question: Have you ever had sex?); age of sexual initiation (assessed by the question: How old were you when you had sex for the first time?); and total number of sexual partners (determined by the question: Overall, with how many people have you ever had sexual relations?) The dependent variable, sexual behavior, was assessed by the question: The last time you had sex, did you or your partner use a condom? The answer was categorized into never had sex, had safe sex (used a condom), and had unprotected sex (did not use a condom).

The explanatory variables were grouped into the following four domains.

1. Sociodemographic characteristics: Gender, age in years $(\leq 13$, $14,15, \geq 16$ ) and ethnic group/skin color (White, Black, Mulatto, Asian origin, Brazilian Indian). Socioeconomic status was assessed by the household assets indicator [30], composed of the assets that had less than a $70 \%$ prevalence in the sample (fixed telephone, washing machine, computer with Internet connection, car, and motorcycle). The weight attributed to the presence of each domestic asset was defined as $100 \%$, subtracted by the relative frequency (\%) of the asset; that is, the rarer the presence of an item in the household, the greater the weight attributed to it. The indicator ranged from 0 to 1 and was divided into terciles (1st tercile, lowest; 2 nd tercile; and 3rd tercile, highest).

2. Psychoactive substances: Alcohol use (no/yes) was defined by drinking at least one cup or dose of any alcoholic beverage in the past 30 days and was assessed by the question, "In the past 30 days, on the days you drank any alcoholic beverage, how many cups or doses did you have?" Similarly, regular smoking (no/yes) was defined by any positive answer to the question, "In the past 30 days, in how many days did you smoke cigarettes?" Experimenting with drugs (no/yes) was obtained by the question, "Have you ever used any drugs, such as marijuana, cocaine, crack, glue, chloroform, ethyl chloride, ecstasy, or others?" We built a single variable that corresponds with the sum of all risk behaviors reported by the teenager (adolescent) and varied from 0 (no risk behavior) to 3 (all three risk behaviors)."

3. Characteristics of the family context: Family composition (lives with farther and mother, lives only with mother, lives only with father, lives with neither); having meals with a parent or equivalent (assessed by the question: Do you usually have lunch or dinner with your parent[s] or whoever is responsible for you?-every day of the week, at least 1 day of the week, rarely, never); parental supervision (measured by the question: In the last 30 days, how frequently did your parent[s], or person responsible for you, really know what you were doing during your spare time?-always/most of the time, sometimes/rarely). 


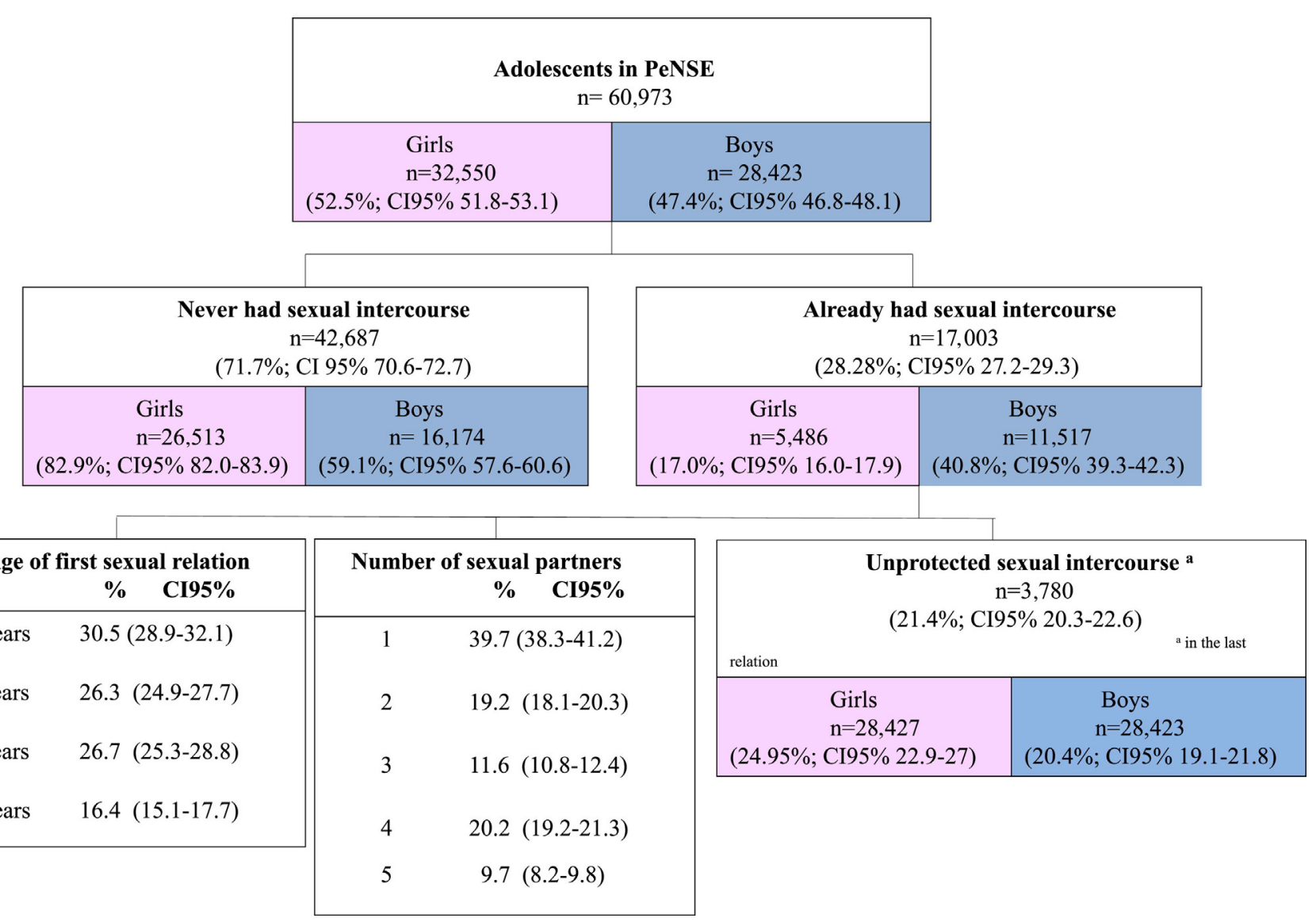

Fig. 1. Sexual behavior in Brazilian adolescents (National Survey of School Health - PeNSE, 2009).

4. Characteristics from the school context: Administration (public or private school); information about free access to condoms (assessed by the question: At school, have you ever received orientation about how to obtain free condoms?-yes, no); information about AIDS or other STDs and/or information about pregnancy prevention (determined by the questions: At school, have you ever received orientation about AIDS or other STDs? [yes, no] and at school, have you ever received orientation about pregnancy prevention? [yes, no]).

\section{Data analysis}

A descriptive analysis was carried out according to the independent variables. The associations between the independent variables and sexual behavior were measured by Person's chisquare test, with a significance level of 0.05 .

Multinomial logistic regression was used to identify individual and contextual variables associated with sexual behavior. The reference category was never had sexual intercourse. Initially, a multinomial univariate analysis was carried out within every domain. Variables with a $p$ under 0.20 were selected for the multivariate model in each domain. A model was built for each group and, subsequently, a final model was conceived, considering all the factors associated with the response variable. Domains were included sequentially: Individual characteristics, followed by behavioral factors, family context and, finally, school context. The magnitude of the associations was determined by the odds ratio (OR), with a confidence interval (CI) of $95 \%$.

When cluster sampling is employed, students' responses cannot be assumed be independent, because school children within the same class are more likely to be similar to each other. This factor was considered in the analysis to correct the design effect caused by the complex sampling procedure adopted, given that cluster sampling tends to produce more standard errors than equivalent sample sizes, obtained from random sampling. The design factor was defined as the ratio between the standard error derived from a complex survey and the one obtained considering a simple random sample. The analysis was carried out with Stata software (version 11.0) using the 'svy' procedure (with weighting factors), appropriate for the analysis of data obtained from a complex sampling design. Using different weights in the proportional estimation, this procedure allows to correct the analysis for the different selection probabilities of each school.

\section{Results}

\section{Demographic characteristics of the sample}

In our sample of students, $52.5 \%$ were girls and $47.5 \%$ boys. Overall, more than two thirds of participants (79.8\%) are aged 14 years or younger ( $23.7 \%$ are 13 years and $47.1 \%, 14$ years). About one third $(28.4 \%)$ are aged 15 years or older. The distribution by race/skin color shows higher proportions of Whites (40.1\%) and mulattos (39.1\%), followed by Blacks (12.9\%), Brazilian Indians (4.1\%), and those of Asian descent (3.7\%).

\section{Sexual behavior}

Altogether, 28.2\% of the PeNSE participants (95\% CI, 27.2-29.3) report having had sexual intercourse at least once in their life, the frequency being higher among boys than among girls (40.8\% vs. 
Table 1

Sexual behavior according to sociodemographic characteristics and use psychoactive substances among adolescents from schools in the 26 Brazilian state capitals and the Federal District

\begin{tabular}{|c|c|c|c|}
\hline & $\begin{array}{l}\text { Never had sexual } \\
\text { relations } \\
\%(95 \% \mathrm{CI})\end{array}$ & $\begin{array}{l}\text { Protected sexual } \\
\text { intercourse }^{*} \\
\%(95 \% \mathrm{CI})\end{array}$ & $\begin{array}{l}\text { Unprotected sexual } \\
\text { intercourse } \\
\%(95 \% \mathrm{CI})\end{array}$ \\
\hline \multicolumn{4}{|c|}{ Sociodemographic factors } \\
\hline \multicolumn{4}{|l|}{ Gender $(n=59,186)$} \\
\hline Male & $59.6(58.7-61.0)$ & $32.1(30.7-33.5)$ & $8.2(7.7-8.8)$ \\
\hline Female & $82.9(82.0-83.9)$ & $12.7(12.0-13.5)$ & $4.2(3.8-4.7)$ \\
\hline \multicolumn{4}{|c|}{ Age, yrs $(n=59,064)$} \\
\hline$\leq 13$ & $87.3(86.3-88.3)$ & $9.4(8.5-10.3)$ & $3.2(2.6-3.8)$ \\
\hline 14 & $77.5(76.4-78.5)$ & $17.8(16.8-18.9)$ & $4.5(4.2-5.0)$ \\
\hline 15 & $55.2(53.5-57.0)$ & $35.0(33.3-36.7)$ & $9.6(8.7-10.7)$ \\
\hline$\geq 16$ & $38.8(36.7-41.1)$ & $47.0(44.7-49.4)$ & $14.0(12.5-15.6)$ \\
\hline \multicolumn{4}{|c|}{ Race/color $(\mathrm{n}=58,119)$} \\
\hline White & $76.1(74.8-77.3)$ & $18.9(17.8-19.9)$ & $4.9(4.4-5.5)$ \\
\hline Black & $63.5(61.5-65.4)$ & $28.1(26.4-29.9)$ & $8.3(7.2-9.5)$ \\
\hline Mulatto & $70.8(69.4-72.2)$ & $22.8(21.6-24.0)$ & $6.3(5.8-6.9)$ \\
\hline Asian descendent & $73.6(70.2-76.8)$ & $18.6(16.0-21.6)$ & $7.6(6.0-9.6)$ \\
\hline Brasilian Indian & $67.3(64.4-70.1)$ & $25.2(16.0-21.6)$ & $7.4(6.1-9.0)$ \\
\hline \multicolumn{4}{|c|}{ Assets indicator, tercile $(\mathrm{n}=56,464)$} \\
\hline $1^{\text {st }}$ & $69.7(68.2-71.2)$ & $22.6(21.3-23.9)$ & $7.6(6.9-8.2)$ \\
\hline $2^{\text {nd }}$ & $73.1(71.7-74.5)$ & $20.6(19.4-21.8)$ & $6.2(5.5-6.9)$ \\
\hline $3^{\text {rd }}$ & $73.2(71.6-74.7)$ & $22.1(20.8-23.5)$ & $4.6(4.1-5.2)$ \\
\hline \multicolumn{4}{|c|}{ Psychoactive substances } \\
\hline \multicolumn{4}{|c|}{ Regular use of alcohol $(n=58,259)$} \\
\hline No & $79.8(78.9-80.7)$ & $15.7(14.9-16.5)$ & $4.4(4.0-4.7)$ \\
\hline Yes & $51.2(49.6-52.9)$ & $38.0(36.5-39.6)$ & $10.6(9.8-11.5)$ \\
\hline \multicolumn{4}{|c|}{ Current smoker $(\mathrm{n}=58,510)$} \\
\hline No & $74.7(73.7-75.7)$ & $19.8(18.9-20,7)$ & $5.4(5.0-5.8)$ \\
\hline Yes & $31.7(28.8-34.7)$ & $51.4(48.3-54.5)$ & $16.8(4.5-19.2)$ \\
\hline \multicolumn{4}{|c|}{ Experimented with drugs lifetime $(n=59,076)$} \\
\hline No & $75.7(74.7-76.7)$ & $19.1(18.3-20.0)$ & $5.1(4.7-5.5)$ \\
\hline Yes & $32.2(29.9-34.7)$ & $50.8(48.4-53.2)$ & $6.1(5.7-6.5)$ \\
\hline
\end{tabular}

$\mathrm{CI}=$ confidence interval.

Notes: All the variables presented $P<.001$, using Person's chi-square test.

* Reported use of protection in the last sexual relation.

Source: National Survey of School Health (PeNSE, 2009).

$17.0 \%$, respectively). Among those who report having had sex, more than one third had their first sexual intercourse at the age of 12 years or younger, which is more common among boys than girls. One fourth declare having had only one sexual partner ever; approximately one fifth (21.4\%) report not having used a condom during the last intercourse, being higher among girls than among boys ( $24.9 \%$ vs. $20.4 \%$, respectively; Fig. 1 ).

With regard to sociodemographic characteristics, the frequency of students who report previous sexual intercourse (with or without the use of a condom) increases with age. Sexual intercourse is more common among teenagers/early adolescents who use alcohol, smoke regularly, and have already tried any illicit drug. Unprotected sex is less frequent among the group of students who declare themselves as White (4.9\%) and more frequent in the group which presents a low household assets indicator (7.6\%; Table 1).

\section{Family and school context}

In the family context, $58.3 \%$ of students live with their father and mother, 55.8\% report that their parents or guardian knew what they were doing during their free time in the past 30 days, and $62.6 \%$ have five or more meals per week with their parent (or guardian). The frequency of students who had sex (with or without a condom) is higher among adolescents who live with neither of their parents or with only one of them, who rarely or never eat meals with their parents (or guardian) and who are submitted to low parental supervision.

In the school context, most of the participants study in state schools (79.2\%) and receive information on free access to condoms
(70.2\%), and on the prevention of pregnancy $(81.3 \%)$ and HIV or other STDs (88.0\%). The frequency of previous sexual intercourse is higher among state schools' adolescent students and among those who do not receive information about reproductive and sexual health (Table 2).

\section{Multivariable analyses}

Table 3 shows the results of the multivariable analysis, after adjusting for the variables from the same group. They reveal that girls present lower chances of having had safe sex (OR, 0.24) and unprotected sex (OR, 0.29). The odds of having had sexual intercourse (with or without protection) increase with age and are lower among white or Asian descent students. Those classified in the higher tercile of the household assets indicator present greater chances of having had safe sex (OR, 1.23) and lesser chances of having had unprotected sex (OR, 0.74). The frequency of previous sexual intercourse (with and without protection) increases according to the number of behavioral risk factors; the higher the number of risk behaviors, the greater the odds of having had sex. This upward gradient is more pronounced for unprotected sex.

In the family context, having sex is associated with living only with the mother or with neither of the parents, rarely eating meals with the parents (or person responsible), and low parental supervision. Living only with the father (OR, 1.47), on the other hand, is associated with safe sex; never eating meals with the parents is associated with unprotected sex (OR, 1.60).

In relation to the school context, receiving school information about free access to condoms and orientation about prevention of STDs was no longer associated with sexual behavior after adjusting for the other variables. Studying in a private school is associated with a lesser chance of having safe sex (OR, 0.58) and unprotected sex (OR, 0.68). Adolescents who do not receive information about AIDS or other STDs and/or about pregnancy prevention at school are more prone to having sexual relations, both protected (OR, 1.33) and unprotected (OR, 1.74).

\section{Discussion}

The results reveal that one in three adolescents have already had sex and that most of them had their first sexual relation very early, at the age of 13 years or younger. One in five sexually active adolescents report not using a condom the last time they had sex. Even if comparable with figures reported in other sites, this frequency of unprotected sex is worrying, because our study population is younger than that in most studies. Our findings confirm evidence concerning the influence of family and school on adolescent sexual behavior, and can contribute to the design of preventive interventions.

Age of sexual initiation varies between different cultures. The frequency of sexual relations among adolescents found in PeNSE is much higher than the one found in a study in China [31], slightly higher than the percentage revealed by a study carried out by the World Health Organization in Europe and North America [2], and lower than the one found by the Youth Risk Behavior Surveillance in the United States [32]. There are, nevertheless, differences between the age ranges used in these studies. In PeNSE, most of the students were aged between 13 and 15 years, so the median was 14 years. In the World Health Organization inquiry, the majority had the age of 15 years. The studies from China and the United States had a wider age range. All these studies also found that the number of incidents of sexual intercourse increases with age and is higher among men.

Around $30 \%$ of the students had their first sexual intercourse at an age of 13 or younger. Early sexual activity can affect negatively the physical, mental, and psychosocial development of adolescents 
Table 2

Sexual behavior according to family and school factors among adolescents from schools in the 26 Brazilian state capitals and the Federal District

\begin{tabular}{|c|c|c|c|}
\hline & Never had sexual relation, \% (95\% CI) & Protected sexual intercourse, $\%$ (95\% CI) & Unprotected sexual intercourse, $\%$ (95\% CI) \\
\hline \multicolumn{4}{|l|}{ Family context } \\
\hline \multicolumn{4}{|c|}{ Family composition $(\mathrm{n}=58,756)$} \\
\hline Mother and father & $76.1(74.9-77.2)$ & $18.8(17.7-19.8)$ & $5.0(4.6-5.5)$ \\
\hline Mother & $67.7(66.3-69.1)$ & $25.0(23.8-26.3)$ & $7.1(6.5-7.8)$ \\
\hline Father & $63.8(60.9-66.6)$ & $28.7(25.9-31.7)$ & $7.4(6.0-9.0)$ \\
\hline None & $60.3(57.5-63.0)$ & $29.5(26.8-32.3)$ & $10.1(8.5-11.9)$ \\
\hline \multicolumn{4}{|c|}{ Meals with parent(s) or other person responsible $(n=58,445)$} \\
\hline Every day of the week & $74.5(73.4-75.7)$ & $20.3(19.3-21.4)$ & $5.0(4.6-5.5)$ \\
\hline At least 1 day & $71.1(69.4-72.8)$ & $22.8(21.3-24.4)$ & $6.0(5.2-6.8)$ \\
\hline Rarely & $69.4(67.2-71.4)$ & $23.1(21.3-25.0)$ & $7.4(6.4-8.7)$ \\
\hline Never & $63.9(61.7-66.0)$ & $25.6(23.8-27.6)$ & $10.3(9.1-11.7)$ \\
\hline \multicolumn{4}{|c|}{ Parents knew what they were doing in the past 30 days $(n=50,078)$} \\
\hline Always/most of the time & $78.3(77.2-79.3)$ & $17.0(16.1-17.9)$ & $4.6(4.2-5.1)$ \\
\hline Sometimes/rarely & $64.2(62.8-65.6)$ & $27.8(26.6-29.1)$ & $7.8(7.2-8.5)$ \\
\hline Never & $64.8(61.7-67.8)$ & $27.3(24.8-30.0)$ & $7.7(6.3-9.4)$ \\
\hline \multicolumn{4}{|l|}{ School context } \\
\hline \multicolumn{4}{|l|}{ Administration $(\mathrm{n}=59,186)$} \\
\hline Public & $69.4(68.1-70.6)$ & $23.8(22.7-24.9)$ & $6.7(6.2-7.2)$ \\
\hline Private & $81.6(80.0-83.1)$ & $14.4(13.2-15.8)$ & $3.8(3.2-4.5)$ \\
\hline \multicolumn{4}{|c|}{ Orientation about free access to condoms $(n=58,453)$} \\
\hline Yes & $70.2(69.1-71.3)$ & $23.6(22.5-24.7)$ & $6.1(5.7-6.5)$ \\
\hline No & $71.2(69.3-73.1)$ & $21.1(19.6-22.6)$ & $7.6(6.7-8.5)$ \\
\hline \multicolumn{4}{|c|}{ Information HIV or other STDs and/or orientation about pregnancy prevention $(n=52,025)$} \\
\hline Yes & $73.4(72.4-74.5)$ & $21.0(20.1-21.9)$ & $5.5(5.1-5.9)$ \\
\hline No & $61.0(58.7-63.3)$ & $28.8(27.0-30.7)$ & $10.1(8.9-11.4)$ \\
\hline
\end{tabular}

$\mathrm{CI}=$ confidence interval; STD, sexually transmitted disease

Notes: All the variables presented $P$ value $<.001$ using Person's chi-square test.

* Reported use of protection in the last sexual relation.

Source: National Survey of School Health (PeNSE, 2009).

$[20,21]$. Adolescents who initiate a sexually active life earlier tend to accumulate more sexual partners over time and, therefore, present greater risks of contracting a STD and of having an unplanned pregnancy. Furthermore, early sexual initiation is associated with a less frequent use of protection $[8,18,33]$. The onset of sexual activity tends to increase with age. Therefore, it is important to introduce sexual education at schools before the 9th grade, when the most of the students are already 14 years old.

In PeNSE, among the adolescents who are already sexually active, $21.4 \%$ did not use protection during their last sexual intercourse. This rate is similar to the one found by the World Organization of Health inquiry (23\%) [2], and much lower than the one found in USA study from the United States (39.8\%) [32]. Our results indicate that one fifth of the students are at risk of exposure to STDs/AIDS and that $25 \%$ of the girls are at risk of becoming pregnant. A longitudinal study with adolescents, Shafii et al [33] revealed that using protection during one's first sexual intercourse is important, because it is associated with use of protection. We know that sexual initiation, as well as the frequency of sexual relations, tends to increase with age. If the percentage of unprotected sex maintains itself close to the identified in this study, the real risk of pregnancy and STDs/AIDS among adolescents also tends to increase.

Gender differences in the prevalence of sexual relations are expected, because girls often initiate sexual activity later than boys. Nonetheless, among girls who have a sexually active life, the use of protection is less frequent than among boys, as observed in other studies with students [2,32]. This finding is concerning; since 1998 in Brazil, the number of AIDS cases among girls 13 to 19 years old increased [34]. Supposedly, the use of a condom requires the cooperation and agreement between both partners. Because women often initiate their sexual life with older and more sexually experienced men, this can inhibit them even more from expressing themselves freely $[25,35]$.

In relation to skin color and the presence of household assets, the difference regarding the use of protection suggests that social inequities affect sexual behavior among Brazilian adolescents. Structural factors, such as national wealth, income inequality, and access to education are important social determinants of adolescent health [36]. In another PeNSE study that analyzed this variable, a higher incidence of sexual relations was found among adolescents whose mothers had low educational levels [37]. In Brazil, schooling levels are lower in women who have lower income and who identify as Black or mulatto $[4,30]$.

Sexual risk behavior in adolescents is associated with the use of psychoactive substances [38]. The use of these substances can affect judgment, decision making, and planning, which, along with the inexperience of adolescents, may influence negatively the choice to use or not protection. We found that the magnitude of the association with unprotected sex, is higher among students who consume alcohol regularly, smoke, and have already experimented with drugs. In a study with African-American adolescents, with the average age of 14 years, the use of substances such as alcohol and drugs was associated with having unprotected sex, after considering the influence of family and friends [11].

Our results show that a good family connection is a protective factor against risky sexual behavior. Living only with the mother or with neither parent is associated with having sexual relations. Living with only the father is associated with higher odds of safe sex. A study in Kenya with students aged on average 16 years found that adolescents who lived with both parents presented slimmer chances of having already had sex [39]. That it is not this condition per se that is a risk factor for sexual activity, but rather that family transitions and interruptions are associated with this condition. During periods of parental separation, the adolescent can experience emotional instability, increasing the odds of engaging in risky sexual activities, including unprotected sex [40].

The presence of parents during the adolescents' main meals is an indicator of parent-child communication. In PeNSE, adolescents who rarely eat meals with their parents have had more sexual relations. Those who never eat meals with their parents present greater odds of having unprotected sex. This result agrees with 
Table 3

Factors associated with sexual behavior among adolescents from schools in the 26 state capitals and the Federal District measured by means of multinomial multiple regression ${ }^{\dagger}$

\begin{tabular}{|c|c|c|}
\hline & $\begin{array}{l}\text { Protected sexual } \\
\text { intercourse* } \\
\text { OR }(95 \% \mathrm{CI})\end{array}$ & $\begin{array}{l}\text { Unprotected sexual } \\
\text { intercourse* OR } \\
(95 \% \mathrm{CI})\end{array}$ \\
\hline \multicolumn{3}{|l|}{ Sociodemographic factors } \\
\hline \multicolumn{3}{|l|}{ Gender } \\
\hline Male & 1 & 1 \\
\hline Female & $0.24(0.22-0.27)^{\ddagger}$ & $0.29(0.25-0.33)^{\ddagger}$ \\
\hline \multicolumn{3}{|l|}{ Age, yrs } \\
\hline$\leq 13$ & 1 & 1 \\
\hline$\overline{14}$ & $1.97(1.71-2.26)^{\ddagger}$ & $1.39(1.10-1.76)^{\S}$ \\
\hline 15 & $4,17(3.57-4.88)^{\ddagger}$ & $3.05(2.35-3.96)^{\ddagger}$ \\
\hline$\geq 16$ & $7.25(6.10-8.63)^{\ddagger}$ & $5.35(4.16-6.87)^{\ddagger}$ \\
\hline \multicolumn{3}{|l|}{ Race/color } \\
\hline White & 1 & 1 \\
\hline Black & $1.23(1.06-1.43)^{\ddagger}$ & $1.34(1.07-1.68)^{\S}$ \\
\hline Mulatto & $1.28(1.15-1.44)^{\S}$ & $1.27(1.07-1.49)^{\S}$ \\
\hline Asian descendant & $0.99(0.79-1.23)$ & $1.63(1.18-2.24)^{\|}$ \\
\hline Brasilian Indian & $1.22(1.01-1.48)^{\|}$ & $1.39(1.04-1.86)^{\|}$ \\
\hline \multicolumn{3}{|l|}{ Assets indicator, tercile } \\
\hline $1^{\text {st }}$ & 1 & 1 \\
\hline $2^{\text {nd }}$ & $0.95(0.86-1.06)$ & $0.82(0.71-0.95)^{\S}$ \\
\hline $3^{\text {rd }}$ & $1.23(1.08-1.39)^{\|}$ & $0.75(0.61-0.92)^{\S}$ \\
\hline \multicolumn{3}{|l|}{ Behavioral factors } \\
\hline \multicolumn{3}{|c|}{ Regular use of alcohol, smoking, and experimenting with drugs } \\
\hline 0 & 1 & 1 \\
\hline 1 & $2.85(2.55-3.18)^{\ddagger}$ & $2.98(2.57-3.45)^{\ddagger}$ \\
\hline 2 & $7.59(6.23-9.23)^{\ddagger}$ & $7.49(5.93-9.46)^{\ddagger}$ \\
\hline 3 & $18.73(14.14-24.81)^{\ddagger}$ & $23.22(16.26-33.14)^{\ddagger}$ \\
\hline \multicolumn{3}{|l|}{ Family context } \\
\hline \multicolumn{3}{|l|}{ Family composition } \\
\hline Mother and father & 1 & 1 \\
\hline Mother & $1.41(1.27-1.57)^{\ddagger}$ & $1.33(1.15-1.55)^{\ddagger}$ \\
\hline Father & $1.47(1.20-1.79)^{\ddagger}$ & $1.15(0.88-1.52)$ \\
\hline None & $1.64(1.33-2.03)^{\ddagger}$ & $1.75(1.42-2.15)^{\ddagger}$ \\
\hline \multicolumn{3}{|c|}{ Meals with parent(s) or other person responsible } \\
\hline At least 1 day & 1 & 1 \\
\hline Rarely & $1.06(0.92-1.22)$ & $1.26(1.03-1.55)^{\ddagger}$ \\
\hline Never & $0.99(0.86-1.14)$ & $1.60(1.31-1.96)^{\|}$ \\
\hline \multicolumn{3}{|l|}{ Parental supervision } \\
\hline Always/most of the time & 1 & 1 \\
\hline Sometimes/rarely & $1.42(1.25-1.62)^{\|}$ & $1.46(1.20-1.77)^{\|}$ \\
\hline Never & $1.35(1.22-1.49)^{\ddagger}$ & $1.28(1.10-1.48)^{\ddagger}$ \\
\hline \multicolumn{3}{|l|}{ School context } \\
\hline \multicolumn{3}{|l|}{ Administration } \\
\hline Public & 1 & 1 \\
\hline Private & $0.58(0.50-0.67)^{\ddagger}$ & $0.68(0.52-0.87)^{\S}$ \\
\hline \multicolumn{3}{|c|}{ Information HIV or other STDs and/or orientation about pregnancy prevention } \\
\hline Yes & 1 & 1 \\
\hline No & $1.33(1.18-1.50)^{\ddagger}$ & $1.74(1.43-2.12)^{\ddagger}$ \\
\hline $\begin{array}{l}\mathrm{CI}=\text { confidence interval; } \mathrm{OR}= \\
* \text { Reported use of protection } \\
\dagger \text { Never had sexual relation } \mathrm{n} \\
\ddagger P<.001 . \\
\S P<.01 . \\
\| P<.05 .\end{array}$ & $\begin{array}{l}\text { Ids ratio; STD = sexuall } \\
\text { the last sexual relation } \\
\text { s used as reference. }\end{array}$ & transmitted disease. \\
\hline Source: National Survey of Scl & ealth (PeNSE, 2009 & \\
\hline
\end{tabular}

other international studies $[9,16]$ and corroborates that good parent-child communication can impact positively adolescent sexual behavior.

Parental supervision is also considered important to prevent sexual risk behaviors in adolescents [5]. In our study, low parental surveillance is positively associated with having protected and unprotected sex. In a longitudinal study in Scotland, with 5,041 adolescents between the age range of 13 and 14 years, low parental supervision predicted unprotected sex at the age of 15 to 16 years [41].

Interventions that facilitate integration between the family and the teenager can have positive effects on the sexual and reproductive health of adolescents $[42,43]$. Outside the family, the school environment is what most influences behavior in general among young people, including sexual behavior [3,42]. In a study of sexually active adolescents, the use of psychoactive substances, low parental control, and family support, among other factors, were independently associated with sexual risk behaviors [13]. A good relationship between parents and adolescents and greater educational aspirations are associated with later sexual initiation, safe sex, and lesser chances of having STDs in the future [16].

In the school context, private school was protective against having sexual relations. In Brazil, school is an unequally distributed social product. Studying in a private school is an indicator of a higher income level, which is often related with more educated parents and, therefore, with better healthcare at home and more access to professional healthcare. Adolescents who did not receive information about AIDS or other STDs and/or information about pregnancy prevention at school present higher chances of having sexual relations in general, in particular unprotected sex. Of Brazilian schools already, $88 \%$ approach the subject HIV or other STDs and $81.3 \%$, pregnancy prevention. There is free distribution of condoms, especially for younger students. Public schools are the second place with more access to condoms, after public healthcare services [34]. An aspect that must be considered is that we do not know the quality and frequency of school orientation about the risk of STDs. The literature suggests that knowledge does not necessarily entail behavioral changes [44].

In Brazil, pregnancy and STDs among adolescents are important public health matters and are both associated with unprotected sex [22-28]. Studies in the country also show that adolescent pregnancy is related with lower family income and dropping out of school [45]. School and family interventions may contribute to increase condom use among young people. Schools are a privileged locus for integrated family-school interventions. In 2007, Brazil initiated the School Health Program, which aims at integrating schools and primary health care, so that adolescents and teachers approach the Family Health teams and reverse.

\section{Strengths and limitations}

The present study was based on a large sample representing adolescents from private and public schools in all Brazilian State Capitals and the Federal District. We investigated whether family and school contextual factors are associated with protected and unprotect sexual activity, after considering the effect of other documented factors.

One limitation is that the data only refers to State Capitals and the Federal District, so we cannot apply these results to adolescents who live in small towns and in rural regions of the country. It is also possible that the students' situation at the time of the study, such as parental living arrangement, had changed since they had had their last sexual intercourse. Nonetheless, the age of sexual initiation is close to the age of most of the adolescents at the time of the study, as the median age of participants is 14 years, and the median age of the first intercourse is 13 years. Thus, for most, the last sexual intercourse was likely to have been close to the actual time of the interview. Moreover, possible changes between the living situation at the time of the last sexual intercourse and the one at the time of the inquiry are likely to affect only a small part of the adolescents, because these changes are not so frequent. In these cases, misclassification would be nondifferential, hence biasing the results toward the null. Unfortunately, we have no information to discriminate whether the first sexual intercourse was consensual or not (abuse). Finally, because of the transversal cut, we were not able to infer the temporal nature of most part of the observed associations. 


\section{Conclusion}

Family and school influence the health and welfare of adolescents and have important implications on adult life. Poor family relationships and low parental monitoring, as well as changes in family composition, can affect negatively the sexual behavior of adolescents. In the school context, not receiving information about sexual and reproductive health increases the chances of having sexual intercourse, and the magnitude of the association is even greater for unprotected sex. Information about pregnancy and STDs/AIDS prevention needs to be disseminated very early as an important measure for the students who initiate their sexual life before the age of 13 years. Our results reinforce the importance of family-school partnership to prevent sexually risky behaviors among adolescents.

\section{Acknowledgments}

Maryane Oliveira-Campos receives a research grants from CAPES (Ministry of Education, Brazil) and Sandhi M Barreto from CNPq (Ministry of Science and Technology, Brazil). Financing provided by the Ministry of Health, Brazil.

\section{References}

[1] Bronfenbrenner U, Ceci SJ. Nature-nurture reconceptualized in developmental perspective: a bioecological model. Psychol Rev 1994;101:568-86.

[2] Currie C, Roberts C, Morgan A, Smith R, Settertobulte W, Samdal O, et al. Young people's health in context: Health Behaviour in School-Aged Children (HBSC) study: international report from the 2001/2002 survey. Copenhagen: WHO Regional Office for Europe; 2004.

[3] Saab H, Klinger D. School differences in adolescent health and wellbeing: findings from the Canadian Health Behavior in School-aged Children Study. Soc Sci Med 2010;70:850-8.

[4] Instituto Brasileiro de Geografia e Estatística. Pesquisa Nacional por Amostra de Domicílios - um panorama da Saúde no Brasil: acesso e utilização dos serviços, condições de saúde e fatores de risco e proteção à saúde (PNAD, 2008). Rio de Janeiro: IBGE; 2010.

[5] Fingerman KL, Bermann E. Applications of family systems theory to the study of adulthood. Intl J Aging Human Dev 2000;51(1):5-29.

[6] Borawski EA, Levers-Landis CE, Lovegreen ID, Trapl ES. Parental monitoring, negotiated unsupervised time, and parental trust: the role of perceived parenting practices in adolescent risk behaviors. J Adolesc Health 2003;33:60-70.

[7] Bersamin M, Todd M, Fisher DA, Hill DL, Grube JW, Walker S. Parenting practices and adolescent sexual behavior: a longitudinal study. J Marriage Family 2008;70:97-112.

[8] Secor-Turner M, Kugler K, Bearinger LH, Sieving R. A global perspective of adolescent sexual and reproductive health: context matters. Adolesc Med 2009;20(3):1005-25.

[9] Jordahl T, Lohman BJ. A bioecological analysis of risk and protective factors associated with early sexual intercourse of young adolescents. Child Youth Serv Rev 2009;31:1272e82.

[10] Boislard PMA, Poulin F. Individual, familial, friends-related and contextual predictors of early sexual intercourse. J Adolesc 2011;34:289-300.

[11] Elkington KS, Bauermeister JA, Zimmerman MA. Do parents and peers matter? A prospective socio-ecological examination of substance use and sexual risk among African American youth. J Adolesc 2011;34:1035-47.

[12] Resnick MD, Bearman PS, Blum RW, Bauman KE, Harris K, Jones J, et al. Protecting adolescents from harm. Findings from de National Longitudinal Study on Adolescent Health. JAMA 1996;278(10):823-32.

[13] Voisin DR, DiClemente RJ, Salazar LF, Crosby RA, Yarber WL. Ecological factors associated with STD risk behaviors among detained female adolescents. Social Work 2006;51(1):71-9.

[14] Voisin DR, Salazar LF, Crosby R, Diclemente RJ, Yarber WL, Staples-Horne M. Teacher connectedness and health-related outcomes among detained adolescents. J Adolesc Health 2005;37(4):337. 17-23.

[15] Voisin DR, Neilands TB. Low school engagement and sexual behaviors among African American youth: examining the influences of gender, peer norms, and gang involvement. Child Youth Serv Rev 2010;32(1):51-7.

[16] Deptula DP, Schoeny ME, Henry DB. How can parents make a difference? Longitudinal associations with adolescent sexual behavior. J Family Psychol 2010;24(6):731-9.
[17] Glasier A, Gülmezoglu AM, Schmid GP, Moreno CG, Van Look PFA. Sexual and reproductive health: a matter of life and death. Lancet 2006;368(9547): 1595-607.

[18] Blum R, Mmari K. Risk and protective factors affecting adolescent reproductive health in developing countries: an analysis of adolescent sexual and reproductive health literature from around the world: summary. Geneva: World Health Organization; 2006.

[19] Gore FM, Bloem PJN, Patton GC, Ferguson J, Joseph V, Coffey C, et al. Globa burden of disease in young people aged 10-24 years: a systematic analysis. Lancet 2011;377(9783):2093-102.

[20] Chen X, Wen S, Fleming N, Demissie K, Rhoads G, Walker M. Teenage pregnancy and adverse birth outcomes: a large population based retrospective cohort study. Intl J Epidemiol 2007;36:368-73.

[21] Eng TR, Butler WT. The hidden epidemic. Washington, DC: National Academy Press; 1997.

[22] Brasil Ministério da Saúde. Pesquisa Nacional de Demografia e Saúde da Criança e da Mulher- PNDS 2006. Brasília: Ministério da Saúde; 2009. p. 300.

[23] Brasil. Ministério da Saúde. Secretaria de Vigilância em Saúde. Programa Nacional de DST e Aids. Prevalências e freqüências relativas de Doenças Sexualmente Transmissíveis (DST) em populações selecionadas de seis capitais brasileiras, 2005. Brasília: Ministério da Saúde; 2008. p. 224.

[24] BRASIL. Ano VIII. Boletim Epidemiológico Aids e DST, Vol. 1. Brasília: Ministério da Saúde; 2011. Sem. Ep. 27/52 a 01/26.

[25] Marinho LFB, Aquino EML, Almeida MCC. Práticas contraceptivas e iniciação sexual entre jovens de três capitais brasileiras. Cadernos de Saúde Pública 2009;25(2):227-39.

[26] Martins LB, Motta, Costa-Paiva LHS da, Osis MJD, Sousa MH de, Pinto-Neto AM et al. Fatores associados ao uso de preservativo masculino e ao conhecimento sobre DST/AIDS em adolescentes de escolas públicas e privadas do Município de São Paulo, Brasil. Cadernos de Saúde Pública 2006;22(2):315-23.

[27] Cruzeiro AL, Souza LD, Silva RA, Pinheiro RT, Rocha CL, Horta BL. Comportamento sexual de risco: fatores associados ao número de parceiros sexuais e ao uso de preservativo em adolescentes. Ciênc Saúde Colet 2010;15(1):1149-58.

[28] Brêtas JR, Ohara CV, Jardim DP, Aguiar Junior WD, Oliveira JR. Aspectos da sexualidade na adolescência. Ciênc Saúde Colet 2011;16(7):3221-8.

[29] Barreto SM, Giatti L, Casado L, de Moura L, Crespo C, Malta D. Contextual factors associated with smoking among Brazilian adolescents. J Epidemiol Community Health 2012;66(8):723-9.

[30] Szwarcwald CL, Souza Júnior PRB, Esteves MAP, Damacena GN, Viacava F. Socio-demographic determinants of self-rated health in Brazil. Cad Saúde Pública 2005;21(1):54-64.

[31] Song Y, Ji CY. Sexual intercourse and high-risk sexual behaviours among a national sample of urban adolescents in China. J Public Health 2010;32(3):312-21.

[32] U.S. Centers for Disease Control and Prevention. Youth Risk Behavior Surveillance- United States, 2011. MMWR 2012;(4):61.

[33] Shafii T, Stovel K, Holmes K. Association between condom use at sexual debut and subsequent sexual trajectories: a longitudinal study using biomarkers. Am J Public Health 2007;97:1090-5.

[34] Brasil Ministério da Saúde. Programa Nacional de DST e AIDS. PCAP: Pesquisa de Conhecimentos, Atitudes e Práticas na População Brasileira, 2008. Brasília: Ministério da Saúde; 2011.

[35] Potsonen R, Kontula O. Adolescents knowledge and attitudes concerning infection and HIV infected persons: how a survey and focus group discussions are suites for researching adolescents' HIV/AIDS knowledge and attitudes. Health Educ Res 1999;14(4):473-84.

[36] Viner RM, Ozer EM, Denny S, Marmot M, Resnick M, Fatusi A, et al. Adolescence and the social determinants of health. Lancet 2012;379(9826):1641-52.

[37] Malta DC, Silva MAI, Mello FCM, Monteiro RA, Porto DL, Sardinha LMV, et al Saúde sexual dos adolescentes segundo a Pesquisa Nacional de Saúde dos Escolares. Revista Brasileira de Epidemiologia 2011;14(1):147-56.

[38] Jackson C, Sweeting H, Haw S. Clustering of substance use and sexual risk behaviour in adolescence: analysis of two cohort studies. BMJ Open 2012;2:e000661. http://dx.doi.org/10.1136/bmjopen-2011-000661.

[39] Kabiru CW, Orpinas P. Factors associated with sexual activity among highschool students in Nairobi, Kenya. J Adolesc 2009;32:1023-39.

[40] Miller BC. Family influences on adolescent sexual and contraceptive behavior. J Sex Res 2002;39(1):22-6.

[41] Wight D, Williamson L, Henderson M. Parental influences on young people's sexual behavior: a longitudinal analysis. J Adolesc 2006;29:473-94.

[42] Gavin LE, Catalano RF, Markham CM. Positive youth development as a strategy to promote adolescent sexual and reproductive health. J Adolesc Health 2010;46(Suppl 3):S1-6.

[43] Campero L, Walker D, Atienzo E, Gutierrez JP. A quasi-experimental evaluation of parents as sexual health educators resulting in delayed sexual initiation and increased access to condoms. J Adolesc 2011;34(2):215-23.

[44] Walker D, Gutierrez JP, Torres P, Bertozzi S. HIV prevention in Mexican schools: prospective randomised evaluation of intervention. BMJ 2006;332(7551): 1189-94.

[45] Almeida MCC, Aquino EML. Adolescent pregnancy and completion of basic education: a study of young people in three state capital cities in Brazil. Cadernos de Saúde Pública 2011;27(12):2386-400. 